OPEN ACCESS

Approved by:

Frontiers Editorial Office

Frontiers Media SA, Switzerland

*Correspondence: Jong Eun Lee

jelee@yuhs.ac

${ }^{\dagger}$ These authors share first authorship

Specialty section

This article was submitted to

Stroke,

a section of the journal

Frontiers in Neurology

Received: 23 October 2020 Accepted: 03 November 2020 Published: 27 November 2020

Citation:

Park J, Chang JY, Kim JY and Lee JE (2020) Corrigendum: Monocyte

Transmodulation: The Next Novel Therapeutic Approach in Overcoming Ischemic Stroke?

Front. Neurol. 11:620560. doi: 10.3389/fneur.2020.620560

\section{Corrigendum: Monocyte Transmodulation: The Next Novel Therapeutic Approach in Overcoming Ischemic Stroke?}

\author{
Joohyun Park ${ }^{1,2+}$, Ji Young Chang ${ }^{1,2 \dagger}$, Jong Youl Kim ${ }^{1}$ and Jong Eun Lee 1,2,3* \\ ${ }^{1}$ Department of Anatomy, Yonsei University College of Medicine, Seoul, South Korea, ${ }^{2}$ Brain Korea 21 Plus Project for \\ Medical Science, Yonsei University College of Medicine, Seoul, South Korea, ${ }^{3}$ Brain Research Institute, Yonsei University \\ College of Medicine, Seoul, South Korea
}

Keywords: ischemic stroke, neuroinflammation, monocytes, monocyte conversion, macrophages

\section{A Corrigendum on}

Monocyte Transmodulation: The Next Novel Therapeutic Approach in Overcoming Ischemic Stroke?

by Park, J., Chang, J. Y., Kim, J. Y., and Lee, J. E. (2020). Front. Neurol. 11:578003. doi: 10.3389/fneur.2020.578003

Shared first authorship between Joohyun Park and Ji Young Chang was mistakenly not mentioned in the authorship list. The corrected authorship, affiliation list and Author Contributions statement are indicated below.

Joohyun Park ${ }^{1,2 \dagger}$, Ji Young Chang ${ }^{1,2 \dagger}$, Jong Youl Kim ${ }^{1}$ and Jong Eun Lee $1,2,3^{*}$

${ }^{1}$ Department of Anatomy, Yonsei University College of Medicine, Seoul, South Korea

${ }^{2}$ Brain Korea 21 Plus Project for Medical Science, Yonsei University College of Medicine, Seoul, South Korea

${ }^{3}$ Brain Research Institute, Yonsei University College of Medicine, Seoul, South Korea

*Correspondence:

Jong Eun Lee

jelee@yuhs.ac

${ }^{\dagger}$ These authors share first authorship

\section{AUTHOR CONTRIBUTIONS}

JP and JC equally contributed to this study. This manuscript was written by JP and JC. JL and JK participated in the discussion and revision. The final manuscript was designed and edited by JL. All authors read and approved the final manuscript.

The authors apologize for this error and state that this does not change the scientific conclusions of the article in any way. The original article has been updated.

Copyright () 2020 Park, Chang, Kim and Lee. This is an open-access article distributed under the terms of the Creative Commons Attribution License (CC BY). The use, distribution or reproduction in other forums is permitted, provided the original author(s) and the copyright owner(s) are credited and that the original publication in this journal is cited, in accordance with accepted academic practice. No use, distribution or reproduction is permitted which does not comply with these terms. 